\title{
The Development of a Measure of Enculturation for Native American Youth ${ }^{1}$
}

\author{
Marc A. Zimmerman ${ }^{2}$ and Jesus Ramirez-Valles \\ University of Michigan
}

Kathleen M. Washienko ${ }^{3}$

University of Washington

Benjamin Walter ${ }^{3}$

Toledo Health Department

Sandra Dyer ${ }^{4}$

Suttons Bay School System

Enculturation is the process by which individuals learn about and identify with their ethnic minority culture. It is distinguished from acculturation which refers to the process by which an ethnic minority individual is assimilated into the majority culture. Three studies with Native American youths are reported that describe the development of a measure of enculturation for Native American youths. Development of a measure of enculturation provides a foundation upon which to build a body of literature that focuses on strengths in a youth's

\footnotetext{
${ }^{1}$ We would like to thank the Tribe that participated in this study and especially the youth and their parents who agreed to participate. We would also like to thank the Tribal staff youth workers who helped us on many aspects of the study. This research was supported by the Center for Substance Abuse Prevention, Grant No. 1 H86 SPO1835-01A1 to the Grand Traverse Band of Ottawa/Chippewa Indians.

${ }^{2}$ All correspondence should be directed to Marc A. Zimmerman, Department of Health Behavior and Health Education, School of Public Health, University of Michigan, 1420 Washington Heights, Ann Arbor, Michigan 48109-2029.

${ }^{3}$ Benjamin Walter and Kathleen Washienko were research assistants on the project during data collection at Time 1 .

${ }^{4}$ Sandra Dyer was the Director for the project upon which this study is based at the time of data collection.
} 
life rather than on deficits. Results of the first study $(\mathrm{n}=120)$, a confirmatory factor analysis, indicated that cultural affinity, Native American identity, and family involvement in traditional activities adequately represent the construct of enculturation. The study also provides some convergent validity for this interpretation. The second study examines factor invariance for enculturation among youths with data from over 2 years $(\mathrm{n}=69)$. The factor structure was similar across time. The third study replicates the factor structure and validity analyses with a new sample $(\mathrm{n}=42)$. Usefulness of the measure for assessing protective factors and stressing ethnicity over simple assessment of race categories is discussed.

KEY WORDS: enculturation; ethnic identity; minority culture; native American.

Enculturation is the process by which individuals learn about and identify with their traditional ethnic culture (Little Soldier, 1985). Although enculturation is considered a lifelong learning experience in which cultural awareness and understanding develops (Wilbert, 1976), if considered as a state of being rather than a process, enculturation may be defined as the extent to which individuals identify with their ethnic culture, feel a sense of pride in their cultural heritage, and participate in traditional cultural activities. Few investigators, however, have studied enculturation.

A related construct is ethnic identity. Ethnic identity may be defined as that part of a person's social identity that results from knowledge about and attachment to a cultural group (Tajfel, 1981). In a review of the research on ethnic identity, Phinney (1990) pointed out that ethnic identity has been operationalized as feelings of belonging to an ethnic group, shared values with an ethnic group, and the performance of cultural traditions. These components, however, are often assessed and considered independently (Rotherman \& Phinney, 1987). A notable exception is a study by Phinney (1992) that reported the development of an ethnic identity measure. The measure contains items that assess self-identification, ethnic practices, a sense of belonging to one's ethnic group, and achievement of ethnic identity.

Ethnic identity may be analogous to enculturation when it is conceptualized as a multidimensional construct that is not linked to mainstream culture. The term enculturation is preferred, however, because ethnic identity is often measured as a unidimensional construct (Rotherman \& Phinney, 1987) and used as a benchmark for assessing integration in the dominant culture (LaFromboise, Coleman, \& Gerton, 1993). Several investigators have also suggested that ethnic identity does not fully capture the enculturation construct because it may not include participation in culturally relevant activities or a connection to one's cultural heritage (Little Soldier, 1985; Oetting 
\& Beauvais, 1991; Trimble, 1983, 1987). For the purposes of the studies reported here, the term enculturation is used to insure that a multidimensional perspective of cultural identity is portrayed. This perspective is consistent with Phinney's (1992) conceptualization of ethnic identity.

Enculturation is especially relevant for Native Americans (NAs) because many efforts have been made to systematically and forcibly assimilate them into the white majority culture. NAs did not immigrate to this country as other nonwhite populations have; rather, they fought with and lost their homes to invading Europeans. As Nicols (1990-1991) pointed out, they have experienced an ongoing process of domination by the majority culture since the early days of the Republic (i.e., 1700s) through the use of missionaries, boarding schools, allotment, and urban relocation. Nevertheless, NA culture and traditions remain, and are beginning to experience a revival.

The development of a measure of enculturation that is particularly relevant for NA populations provides a foundation upon which to build research that focuses on unique strengths in the NA community. The construct also provides a framework to learn about the NA community that may be more consistent with their life experience. It focuses attention on the social niche and traditions of their native group, rather than on the dominant society in which they may not be welcome. This is significant, because enculturation is culturally relevant and does not require mainstream norms as a point of comparison. The construct of enculturation also requires researchers to consider cultural diversity in ways that do not emphasize mainstream culture. Thus, the notion of person-environment fit may be defined in terms of ethnicity and not some absolute criterion that typically mirrors the dominant culture. Enculturation may also direct attention to the development of programs that help participants connect to their cultural heritage and strengthen their sense of community.

Three studies are described that first establish the factor structure of a three-component measure of NA enculturation and replicate the structure over time within the same sample, and cross-sectionally with a new sample. Convergent validity of the measure is also studied. It should be pointed out that Tribal staff who work with Tribal youths helped with the research design and protocols. They worked with the research team to develop strategies for sample selection, data collection, and measurement development. They helped identify NA youths to be included in the study, and because they knew these youths, they were able to confirm their Tribal membership. They also helped to recruit youths (and find them again in Year 2), and assisted in obtaining parental consent. In addition, the staff helped develop the survey protocol. They selected existing scales and, in some cases, items from scales that they wanted to include in the study. 


\section{STUDY 1}

\section{Methods}

\section{Tribal Context}

The 2,250-member Tribe included in this study is based in the northern part of one state in the Midwestern United States. The Tribe is a partnership of individuals from Odawa and Ojibway heritage. ${ }^{5}$ Tribal land comprises 400 acres in locations throughout a six-county area. Only 800 members live in this area that includes reservation land. Most members live off the reservation in nearby towns. Approximately 300 of the members who live in the six-county Tribal service area are from 7 to 18 years old. The Tribe maintains several satellite offices in towns near the reservation to provide cultural, recreational, and educational services to members. Tribal documents indicate that $75 \%$ of the households live below the poverty level. The reservation comprises private homes, a public housing unit, a nursing home for elders, a recreational center for youth, a health clinic, a casino and motel, and Tribal government offices. Most of the children attend public schools in white middle class communities around the reservation, but the Tribe is beginning to develop a reservation school.

\section{Sampling Procedure}

Youths were sampled in several ways. Those who attended a summer camp for NA youths were asked to complete a questionnaire $(n=50)$. Youths who attended a Tribal event (i.e., Family Olympics) were asked to complete a questionnaire $(n=13)$. Staff who work with Tribal youths also canvassed door-to-door on the reservation to recruit participants $(n=10)$. Ten youths were recruited from a school program list (Title V) with the assistance of the Title V coordinator. Nine youths were selected from the participant list of the Johnson O'Malley program (JOM), a federal program of the Bureau of Indian Affairs which financially assists NA children to participate in cultural projects and activities. Staff also asked participants of the local Upward Bound program to complete questionnaires $(n=14)$. Fifteen children of Tribal employees were also recruited. The final sample included youths who represented all six counties covered by the Tribe, including youths from the reservation. Consent from one of the youths' parents or guardians was obtained for all youth. Youths were offered vouchers for purchasing craft materials as an incentive to participate in the study.

\footnotetext{
${ }^{5}$ The Anglicized version of these Tribal names are Ottawa and Chippewa, respectively.
} 
Sample. A final sample of 120 youths was obtained. This represents nearly $40 \%$ of the Tribal youths. Their mean age was $11.5(S D=2.8)$. The youth ranged from 7-18 years old; 2 were 18 and 5 were 7 years old. The skewness for the age distribution was .396 . The sample included $50 \% \mathrm{fe}$ males. Forty percent of the youths lived on the reservation, but all Tribal activities and community cultural events were geographically accessible to all youths.

\section{Survey Procedure}

Questionnaires were administered in several locations including the Tribe's satellite offices, the Tribal youth center, the camp setting, churches, the local community college, and the youths' homes. In some instances, the children under 10 years of age had some difficulty with comprehension of specific words and items in the questionnaire. A research staff member read the items to these youths and assisted them in completing the questionnaire. This assistance was necessary for approximately 20 youths. We did not code which youths needed assistance and which did not, so we could not determine if these youths differed in their responses. These youths were included in all analyses for several reasons: (a) the help they received was for clarification of a question or word only; (b) they were not coached in their responses; (c) their responses were private; and (d) several items or words for which they needed assistance were not part of the data reported in this study.

\section{Measures}

\section{Enculturation Measures}

We hypothesized that cultural affinity, cultural identity, and involvement in cultural activities would form a single factor that could be interpreted as enculturation.

Cultural Affinity. Cultural affinity is defined as youths' pride and interest in their NA culture. A five-item scale was developed that used a 5-point Likert scale to assess cultural affinity. Questions were (a) How important is it to you to maintain your Indian identity, values, and practices? (b) How much do you know about your Native American culture? (c) How interested are you in learning more about your Native American culture? (d) How different do you think Indian culture is from White culture? and (e) I am proud to be a Native American. Items 1 and 4 listed above came from King's Acculturation Scale (1992). These items were combined into 
a scale based upon exploratory factor analytic results. The factor analysis resulted in a single factor accounting for $47 \%$ of the total variance; the factor loadings for items ranged from .52 to .81 (commonalities ranged from .32 to .66). The Cronbach alpha for this scale was .70. It should be noted that these results are based on the sample from Study 1 only $(n=120)$.

Family Activities. Respondents were asked to complete a checklist of nine activities which they did with their families. The activities included ghost suppers, Pow Wows, sweat lodges, seasonal feasts, naming ceremonies, healings, giveaways, fasting, and learning lodge. Scores could range from 0 (no activities checked) to 9 (all activities checked).

Native American Identity. A single question was used to measure NA identity, "Do you see yourself as American Indian?" with four possible responses: 0 (not at all); 1 (a little); 2 (some); 3 (a lot).

\section{Convergent Validity Measures}

Four variables were used to assess the convergent validity of the enculturation factor: youths' perception of mother's NA identity; youths' perception of father's NA identity; number of NA friends; and self-esteem. Convergent validity would be supported if these variables were correlated positively with enculturation.

Mothers' and Fathers' Native American Identity. Native American identity of the father and the mother was measured separately with a single item. Youths were asked to indicate on a 4-item Likert scale ranging from 1 (not at all) to 4 (mostly all) how much their mothers and fathers consider themselves to be Native American. Enculturation is expected to correlate positively with youths' perceptions of both their parents' NA identity because one part of the measure of enculturation is family cultural activities. Parents also provide the primary context for socializing youth in traditional NA customs and values.

Native American Friends. Number of NA friends was measured with a single question about how many of their close friends were NA. The item used a 4-point scale: 0 (none) to 3 (most of them). Youth who report higher levels of enculturation are expected to have more close friends who are NA because it is one indication that they are part of a NA community.

Self-Esteem. Self-esteem was measured with nine 5-point Likert items. Tribal staff chose items from several existing self-esteem scales (e.g., Rosenberg, 1965) because they did not think all the items in any one scale would be appropriate for their youth. Principle components analysis of 
Study 1 data was used to form the measure. A single factor accounted for $36 \%$ of the total variance. The factor loadings' absolute values ranged from .36 to .74 (commonalities ranged from .44 to .73 ). The Cronbach alpha for the scale was .76. Enculturation is expected to be related to higher self-esteem because one's self-worth is expected to be associated with acceptance and pride of one's cultural background.

\section{Data Analytic Procedures}

Confirmatory factor analysis (CFA) was conducted using the structural equations software program (EQS; Bentler, 1989). Several techniques were employed to evaluate the model. The significance of the factor loadings was examined, as well as the chi-square values, the Comparative Fit Index (CFI), the Normed Fit Index (NFI), and Nonnormed Fit Index (NNFI). The NFI ranges from 0 to 1 with higher values indicating better fit. One disadvantage of the NFI is that in small samples it may not reach 1.0 when the model is correct. The NNFI adjusts the fitness to the degrees of freedom. Bentler has suggested that NNFI has the advantage of reflecting fit very well, independent of the sample size. The CFI can help avoid the problems of underestimation related to the NFI and tends to have more stability than the NNFI.

\section{Results and Discussion}

Descriptive statistics for all of the measures used are presented in Table I, The measures are described briefly below. The same measures are used in all three studies reported, but they are presented only here to avoid redundancy. Table I includes descriptive statistics for all three studies.

Table II presents the factor loadings and their standard errors for the CFA model. All the loadings are significant and in the expected direction. For this model $\chi^{2}(1)=1.31, p=.251$; NFI is .958; NNFI is .967; and CFI is .989. These results provide initial support for the hypothesized measurement model of enculturation.

A factor score for enculturation was created for the sample by summing the standardized scores for cultural affinity, NA identity, and family activities. Table III presents the correlations of the factor score with the four criterion variables. All of the correlations except father's NA identity are significant, and all are in the expected direction (i.e., positive). These results provide evidence of convergent validity for the measure of enculturation. 
Table I. Descriptive Statistics for All Variables Across the Three Studies

\begin{tabular}{lccr}
\hline Variable & $\begin{array}{c}\text { Study 1 } \\
(n=120)\end{array}$ & $\begin{array}{c}\text { Study 2 } \\
(n=50)\end{array}$ & $\begin{array}{c}\text { Study } \\
(n=40)\end{array}$ \\
\hline Culture affinity & & & \\
$M$ & 3.92 & 4.03 & 4.04 \\
$S D$ & 0.80 & 0.75 & 0.78 \\
Skewness & -1.21 & -1.29 & -1.47 \\
Range & $1-5$ & $1.8-5$ & $1-5$
\end{tabular}

Family activities

$\begin{array}{llll}M & 2.51 & 2.67 & 2.21 \\ S D & 2.17 & 2.02 & 2.38 \\ \text { Skewness } & 1.24 & 0.43 & 1.40 \\ \text { Range } & 0-9 & 0-8 & 0-9\end{array}$

NA identity

$\begin{array}{lrrr}M & 2.40 & 2.39 & 2.16 \\ S D & 0.70 & 0.73 & 0.89 \\ \text { Skewness } & -0.74 & -0.77 & -0.69 \\ \text { Range } & 1-3 & 1-3 & 0-3\end{array}$

No. of NA friends

$\begin{array}{lccc}M & 1.92 & 2.23 & 1.95 \\ S D & 0.97 & 0.74 & 1.02 \\ \text { Skewness } & -0.62 & -0.70 & -0.65 \\ \text { Range } & 0-3 & 0-3 & 0-3\end{array}$

Mother's NA identity

$M$

1.90

2.32

2.02

SD $\quad 1.07$

1.17

1.27

Skewness

$-0.66$

$-0.29$

$-0.17$

Range

0-3

0-3

0-3

Father's NA identity

\begin{tabular}{lccc}
$M$ & 1.48 & 2.23 & 1.87 \\
$S D$ & 1.26 & 1.25 & 1.26 \\
Skewness & -0.03 & -0.43 & -0.15 \\
Range & $0-3$ & $0-3$ & $0-3$ \\
& & & \\
elf-esteem & & & \\
$M$ & 4.09 & 4.12 & 4.09 \\
SD & 0.66 & 0.54 & 0.76 \\
Skewness & -0.56 & -0.81 & -1.52 \\
Range & $2.33-5$ & $2.56-5$ & $1-5$ \\
\hline
\end{tabular}




\section{STUDY 2}

\section{Methods}

\section{Sample Follow-up Procedure}

Time 2 data collection took place 1 year after Time 1. Follow-up participants were mostly contacted through the Public School system. Principals, counselors, and NA Education (i.e., Title V) staff from elementary, junior, and high schools, assisted in locating Time 1 respondents and providing access to them during the school day. Thirty-five youths who participated in Year 1 were called in groups and completed the questionnaire in school. Another 24 youths who participated in Year 1 completed their questionnaires before or after a youth center activity (e.g., youth center, canoe trip). An additional 10 youths who were not reached at the schools or during program activities were visited at their homes and asked to complete a questionnaire.

Fewer than 15 youths required assistance completing the Time 2 questionnaire. Some of the youths requiring assistance at Time 1 may also have dropped out of the study at Time 2 . Youths who needed assistance were given clarifying information, but were not prompted for particular responses. As at Time 1, they also completed their responses in private.

Sample. Data from 69 youths were obtained from Time 1 and Time 2 data collection for a response rate of 53\%. Their mean age was 11.5 $(S D=2.8)$. The sample included $58 \%$ females. Analyses comparing youths who participated in both years versus those who completed only the Time 1 questionnaire were conducted. Attrition analyses comparing youths who completed Time 2 questionnaires and those who dropped out of the study indicate that males were more likely than females to leave the study. No other differences were found.

\section{Data Analytic Procedures}

To assess the factor invariance, data on Time 1 and Time 2 of this sample were analyzed. The most restricted of the possible hypotheses was tested first. The form of the measurement models was hypothesized to be the same, as well as the coefficients linking the latent to the observed variables and the error terms for the observed variables. Given the time sequence of the data, the error terms of the observed variables were hypothesized to be correlated from Time 1 to Time 2. Also, a causal path from the latent variable in Time 1 to the latent variable in Time 2 was allowed to vary. To evaluate the model, Lagrange multiplier tests for releasing constraints were conducted (Bentler, 1989 ), and the fit indexes described earlier were examined. 
Table II. Unstandardized Factor Loadings and Standard Errors (and Standardized Factor Loading and Errors) for the Confirmatory Factor Analysis ${ }^{a}$

\begin{tabular}{lccc}
\hline Variable & $\begin{array}{c}\text { Study } 1 \\
(n=120)\end{array}$ & $\begin{array}{c}\text { Study } 2 \\
(n=50)\end{array}$ & $\begin{array}{c}\text { Study } 3 \\
(n=40)\end{array}$ \\
\hline $\begin{array}{l}\text { Culture affinity } \\
\text { Factor loading }\end{array}$ & .643 & .577 & .521 \\
& $(.795)$ & $(.585)$ & $(.657)$ \\
Standard error & .125 & .256 & .156 \\
& $(.607)$ & $(.811)$ & $(.754)$ \\
Family activities & & & \\
Factor loading & & & 1.0 \\
& 1.0 & $(.421)$ & $(.573)$ \\
Standard error & $(.443)$ & - & - \\
& - & $(.907)$ & $(.819)$ \\
Native American identity & $(.896)$ & & \\
Factor loading & & .552 & .511 \\
& .351 & $(.583)$ & $(.675)$ \\
Standard error & $(.503)$ & .238 & .150 \\
& .084 & $(.812)$ & $(.738)$ \\
\hline
\end{tabular}

${ }^{a}$ All factor loadings are significant beyond the .05 level.

${ }^{b}$ Scalar indicator.

\section{Results and Discussion}

The model of enculturation with the error terms and the paths from the indicator variables to the latent variables constrained to equality had a $\chi^{2}(10)=13.91, p=.176$, and fit indexes of .826 (NFI), .909 (NNFI), and .940 (CFI). Table II shows the factor loadings and their standard errors. All the loadings are significant as well as the causal path from the latent variable in Time 1 to the one in Time $2(.538, S E=.204)$. The Lagrange multiplier test for releasing the five constraints showed none of them to be statistically significant $(p>.06)$ and they were not made to freely vary in this analysis. In addition, the 1-year test-retest reliability for the factor scores was .50 . These results provide evidence that the factor structure for the proposed measurement model is consistent over time. 


\section{STUDY 3}

\section{Methods}

\section{Survey Procedure}

Youths for Study 3 were recruited at the same time follow-up youths were contacted during Year 2 data collection. New participants recruited at the schools were informed of the purpose of the evaluation and completed the questionnaire in school. Twelve students of the 32 new youth who were contacted through this procedure agreed to participate. Thirty new participants were also recruited during Tribal youth program activities. They were asked to complete the questionnaire either before the activity started or at the end of the activity. All of these youths completed questionnaires.

Sample. Data from 42 youths who did not complete questionnaires during the first year of the study were obtained during Time 2 data collection. Their mean age was $11.5(S D=2.8)$. The sample included 58\% females.

\section{Data Analytic Procedures}

A CFA was applied in this new sample, with the same measurement model defined in Study 1 . The same indexes were examined to evaluate the model.

\section{Results and Discussion}

All factor loadings in this CFA were in the expected direction and statistically significant. Table II presents these factor loadings with their standard errors. For this model, $\chi^{2}(1)=1.01, p=.313$; its fit indexes were .923 (NFI), .996 (NNFI), and .999 (CFI).

A factor score was created for this sample using the same procedures as in Study 1 (i.e., standardize and sum components). Table III shows the factor correlations with the four criterion variables. Only self-esteem is significantly correlated with enculturation. These results closely resemble those found in Study 1, and provide additional support for the proposed conceptual and operational model of enculturation. 
Table III. Correlations of Factor Scores with Criterion Variables for Study 1 and Study 3

\begin{tabular}{lcc}
\hline & \multicolumn{2}{c}{ Enculturation factor } \\
\cline { 2 - 3 } Variable & Study 1 & Study 3 \\
\hline No. of NA friends & $.37^{a}$ & .18 \\
Mother's NA identity & $.36^{a}$ & .24 \\
Father's NA identity & $.21^{b}$ & .03 \\
Self-esteem & $.21^{a}$ & $.32^{a}$ \\
\hline
\end{tabular}

${ }^{a} p<.05$.

${ }^{b}$ This correlation is based on only 77 individuals because of missing data. Most of the youths with missing data could not answer this item as they did not have a father for which they could respond.

\section{GENERAL DISCUSSION}

The conceptual framework of NA enculturation that incorporated cultural identity, cultural affinity, and involvement in traditional activities was supported in three separate analyses using confirmatory factor analysis. Replication of the factor structure over time and in an independent sample suggests that the factor solution is stable. The measurement model of enculturation supported by the similar results across these studies is consistent with the theoretical framework of enculturation presented by others (Little Soldier, 1985; Oetting \& Beauvais, 1991; Trimble, 1983, 1987). The results are also consistent with more general multidimensional models of ethnic identity (Phinney, 1992).

The results of the correlational analyses also provide validating evidence for the measure. The positive correlations with self-esteem are consistent with our hypotheses and other studies (Grossman, Wirt, \& Davids, 1985; Phinney \& Alipuria, 1990; Phinney \& Chavira, 1992). Phinney and Chavira (1992), for example, found that ethnic identity was associated with increasing levels of self-esteem among nonwhite adolescents over a 3-year period (from 16 to 19 years old). Researchers have also found that ethnic identity is associated with African American adolescents' overall selfconcept (Aries \& Moorehead, 1989; Helms, 1990). Our results build upa this research by extending the link between self-esteem and enculturation for NA youths. 
The measure of enculturation reported could be used to explore a protective mechanism among NAs that is culturally relevant. Protective factors work to either mitigate the negative effects of a risk factor (risk/protective mechanism) or to enhance the effects of another variable found to decrease the probability of a problem behavior (protective/protective mechanism) (Brook, Brook, Gordon, \& Whiteman, 1990; Zimmerman \& Arunkumar, 1994). Enculturation, for example, may operate to protect NA youths from using alcohol and other drugs because these behaviors are not condoned in a traditional NA life-style. Zimmerman, Ramirez, Washienko, Walter, and Dyer (1994) found enculturation to strengthen the negative relationship between self-esteem and alcohol and substance use (i.e., a protective/protective effect) among NA youths. Enculturation provides researchers with a construct that focuses attention on a positive aspect of minority culture that may be supported and strengthened in programs designed to prevent deleterious outcomes, or promote healthy functioning.

A measure of enculturation enables research on youths' biculturalism by providing a means for assessing their relationship with their native culture while they are also negotiating integration into mainstream culture. Youths may, for example, need to develop a psychological tie to their native culture before biculturalism becomes an issue. As minority youths' affinity to their native culture increases, they will also eventually have to develop some relationship with the majority culture. LaFromboise et al. (1993) suggested that nonmainstream youths must negotiate between two cultural worlds. They describe five different models of biculturalism - assimilation, acculturation, alternation, multicultural, and fusion - that explain how individuals integrate their cultural heritage with mainstream society. While enculturation is not linked to any culture other than one's ethnic lineage, the relationship nonmainstream youths develop with the dominant culture may define the extent to which they develop into healthy adults.

Markstrom-Adams and Spencer (1994) pointed out that group membership is an essential component of identity formation, especially for minority adolescents. Helping minority youths identify with, develop a sense of pride for, and participate in traditional cultural activities may be an effective intervention strategy for enhancing their self-esteem and promoting their sense of community. Sense of community may also help minority youths cope with their biculturalism. Thus, the construct may provide researchers with a theoretical framework for studying minority youths' development that is rooted in the life experiences of the youths' cultural heritage. 
The construct of enculturation also provides researchers with a psychologically meaningful perspective of ethnicity, rather than the more limited approach of using demographic indicators such as race (Williams, Lavizzo-Mourey, \& Warren, 1994). Williams et al. (1994) pointed out that simple comparisons by race may not be meaningful because they fail to account for within-group variation regarding social and cultural characteristics. Enculturation invites attention to diversity and ethnicity rather than emphasizing mainstream culture and physical descriptions (i.e., race categories). A psychometrically sound measure of enculturation is an essential step for understanding within-group heterogeneity, and more precisely identifying distinct ethnic groupings.

Several limitations of the studies presented suggest that further testing of the measure is also necessary. First, the measure was assessed with relatively small samples. This limitation is somewhat mitigated by the fact that the results replicated over time and across samples. It is also noteworthy that the sample upon which the initial factor structure was developed did have a 40 to 1 ratio of respondents to measures. The small sample in Study 3 may also partly explain why the validating criterion variables were not statistically significant.

Future research needs to test the measure with larger samples, other Odawa and Ojibway youths, and other NA Tribal groups. This scale may not be appropriate for youth from other Tribes for several reasons. First, NA youths from Tribes where most members live on the reservation may be exposed more consistently to cultural traditions and life-styles than the youths in the present study. Second, youths who attend reservation schools may have different feelings about their NA heritage because they may not be subjected to dominant social values or prejudices. Third, the cultural activities assessed may not generalize across all NA groups. Researchers working with other Tribes need to engage in collaborative efforts to identify relevant cultural behaviors.

A second limitation of the studies is that the samples were not randomly selected. Though random sampling would have been the desired approach, it was not practical. The youths attend many schools making it impractical to randomly select from school lists. This is further complicated by the fact that NA youths are not identifiable on school lists. The sampling procedure did, however, select youths from several settings and represented a large proportion of the youths the Tribe considers to be members.

A third limitation is that all the data were based on youths self-reports. It would be more compelling validation if, for example, enculturation was correlated with parents' rating of their own NA identity rather than on the youths' perceptions of their parents' identity. We did, however, collect data 
only from youths whom the Tribe considered to be members, which provided an objective assessment of the respondents' identity. This was a useful strategy because we did not select youths based on their self-reports of NA identity, which may have restricted the variance of the enculturation measures. The low response rate from Time 1 to Time 2 is also a limitation of the study. Youths who left the study, however, were similar on most variables to those who remained.

The age range of the respondents also raises some concern. Seventy percent of the youths were between 9 and 14 years old. Aboud (1987) pointed out, however, that children's ethnic orientation forms between 4 and 8 years old, and that attitudes about their ethnic identity are formed between the ages of 8 and 12. Future research should include both a more homogenous age range and explore how enculturation may relate to other developmental changes such as identity formation. Rosenthal (1987), for example, pointed out that ethnic identification is a vital developmental task for adolescents who are not part of the mainstream culture. Phinney and Rotherman (1987) also pointed out that enculturation influences development, and that these influences vary by developmental period.

These limitations notwithstanding, the three studies provide initial psychometric evidence for a multidimensional measure of NA enculturation. A measure of enculturation is useful because it can be used to study culturally relevant moderating effects for deleterious NA adolescent behaviors (e.g., alcohol and drug use, delinquency). The construct of enculturation may also help researchers explore person-environment fit by assessing the extent to which persons are linked to their cultural group and how that connection (or lack thereof) may promote or inhibit beneficial outcomes. Finally, enculturation helps us rethink our notions of race and cultural diversity because it provides a more exacting approach to ethnic groupings that are not necessarily linked to the dominant culture.

\section{REFERENCES}

Aboud, F. E. (1987). The development of ethnic self-identification and attitudes. In J. S. Phinney \& M. J. Rotherman (Eds.), Children's ethnic socialization: Pluralism and development (pp. 32-55). Newbury Park, CA: Sage.

Aries, E., \& Moorehead, K. (1989). The importance of ethnicity in the development of identity of Black adolescents. Psychological Reports, 65, 75-82.

Bentler, P. M. (1989). EQS structural equations program manual. Los Angeles, CA: BMDP Statistical Software.

Brook, J. S., Brook, D. W., Gordon, A. S., \& Whiteman, M. (1990). The psychosocial etiology of adolescent drug use: A family interactional approach. Genetic, Social, and General Psychology Monographs, 116, 111-267. 
Grossman, B., Wirt, R., \& Davids, A. (1985). Self-esteem, ethnic identity, and behavioral adjustment among Anglo and Chicano adolescents in West Texas. Joumal of Adolescence, $8,57-68$.

Helms, J. (1990). Black and white racial identity: Theory, research, and practice. New York: Greenwood.

King, J. (1992). Acculturation scale. Denver, CO: National Center for American Indian/Alaska Native Mental Health Research.

LaFromboise, T., Coleman, H. L. K., \& Gerton, J. (1993). Psychological impact of biculturalism: Evidence and theory. Psychological Bulletin, 114, 393-412.

Little Soldier, L. (1985). To soar with the eagles: Enculturation and acculturation of Indian children. Childhood Education, 61, 185-191.

Markstrom-Adams, C., \& Spencer, M. (1994). A model of identity intervention with minority adolescents. In S. L. Archer (Ed.), Interventions for adolescent identity development (pp. 84-102). Thousand Oaks, CA: Sage.

Nicols, R. L. (1990-1991). Native American survival in an integrationist society. Joumal of American Ethnic History, 10, 87-93.

Oetting, E. R., \& Beauvais, F. (1991). Orthogonal cultural identification theory: The cultural identification of minority adolescents. International Journal of the Addictions, 25, 655-685.

Phinney, J. S. (1990). Ethnic identity in adolescents and adults: Review of research. Psychological Bulletin, 108, 499-514.

Phinney, J. S. (1992). The multigroup ethnic identity measure: A new scale for use with diverse groups. Journal of Adolescent Research, 7, 156-176.

Phinney, J. S., \& Alipuria, L. L. (1990). Ethnic identity in college students from four ethnic groups. Journal of Adolescence, 13, 171-183.

Phinney, J. S., \& Chavira, V. (1992). Ethnic identity and self-esteem: An exploratory longitudinal study. Journal of Adolescence, 15, 271-281.

Phinney, J. S., \& Rotherman, M. J. (1987). Children's ethnic socialization: Themes and implications. In J. S. Phinney \& M. J. Rotherman (Eds.), Children's ethnic socialization: Pluralism and development (pp. 274-292). Newbury Park, CA: Sage.

Rosenberg, M. (1965). Society and the adolescent self-image. Princeton, NJ: Princeton University Press.

Rosenthal, D. A. (1987). Ethnic identity development in adolescents. In J. S. Phinney \& M. J. Rotherman (Eds.), Children's ethnic socialization: Pluralism and development (pp. 156-179). Newbury Park, CA: Sage.

Rotherman, M. J., \& Phinney, J. S. (1987). Introduction: Definitions and perspectives in the study of children's ethnic socialization. In J. S. Phinney \& M. J. Rotherman (Eds.), Children's ethnic socialization: Pluralism and development (pp. 10-28). Newbury Park, CA: Sage.

Tajfel, H. (1981). Human groups and social categories. New York: Cambridge University Press.

Trimble, J. E. (1983). Stalking the wily emic: Alternatives to cross-cultural measurement. In S. H. Irvine \& J. W. Berry (Eds.), Human assessment and cultural factors (pp. 259-273). New York: Plenum Press.

Trimble, J. E. (1987). Multilinearity of acculturation: Person-situation interactions. In D. M. Keats, D. Munro, \& L. Mann (Eds.), Heterogeneity in cross-cultural psychology (pp. 173-186). Amsterdam: Swets \& Zeitlinger.

Wilbert, J. (1976). Introduction. In J. Wilbert (Ed.), Enculturation in Latin America: An anthology (pp. 1-28). Los Angeles, CA: UCLA Latin American Center for Publications.

Williams, D. R., Lavizzo-Mourey, R., \& Warren, R. C. (1994). Concepts of race and health status in America. Public Health Reports, 109, 26-40.

Zimmerman, M. A., \& Arunkumar, R. (1994). Resiliency research: Implications for schools and policy. Social Policy Report, 7, 1-17.

Zimmerman, M. A., Ramirez, J., Washienko, K. M., Walter, B., \& Dyer, S. (1994). The enculturation hypothesis: Exploring direct and protective effects among Native American youth. In H. I. McCubbin, E. A. Thompson, \& A. I. Thompson (Eds.), Resiliency in ethnic minority families, Vol. 1. Native and immigrant American families (pp. 199-220). Madison: University of Wisconsin. 